\title{
Perception and Misperception of Health Enhancing Physical Activity among Urban Community Dwellers in Ibadan, Nigeria: Profiling the Underestimators, the Overestimators, and the Realists
}

\author{
Ade F. Adeniyi ${ }^{1}$, Omoyemi O. Ogwumike ${ }^{1} \&$ Faola D. Adewumi ${ }^{1}$ \\ ${ }^{1}$ Unit of Sports Physiotherapy and Health Promotion, Department of Physiotherapy, College of Medicine, \\ University of Ibadan, Ibadan, Nigeria \\ Correspondence: Ade F. Adeniyi, Department of Physiotherapy, College of Medicine, University of Ibadan, \\ Ibadan, Nigeria. Tel: 234-80-5732-5888. E-Mail: adeniyifatai@yahoo.co.uk
}

Received: February 21, 2016

doi:10.5539/gjhs.v8n12p248
Accepted: April 27, 2016 Online Published: May 6, 2016

URL: http://dx.doi.org/10.5539/gjhs.v8n12p248

\begin{abstract}
Background: The ability to initiate and sustain health enhancing behaviour including physical activity requires appropriate self-perception of such activities. This study was conducted to investigate whether a group of Nigerian urban community dwellers are able to demonstrate a good perception of their physical activity behaviour.

Methodology: The study was a cross-sectional survey of 1,153 urban community dwellers from three local government areas of Ibadan, Southwest Nigeria. Physical activity perception was assessed first; by self-rating of their physical activity based on a moderate-level physical activity vignette, followed by comparison with a more objective measure using the Short Questionnaire to Assess Health-Enhancing Physical Activity (SQUASH). Participants were thereafter classified as underestimators, overestimators, realistic actives or realistic inactives. Data were analysed using descriptive and inferential statistics, with the influence of sociodemographic characteristics on physical activity perception of participants tested with multiple logistic regression analyses at $\mathrm{p}<0.05$.
\end{abstract}

Results: A total of 604 (52.4\%) of the community dwellers were physically inactive, but only 269 (23.3\%) correctly rated themselves as inactive, 335 (29.1\%) participants overestimated their physical activity level and $2.7 \%$ underestimated theirs. The odds of overestimation of physical activity was higher in middle-aged participants $(\mathrm{OR}=2.16 ; 95 \% \mathrm{CI}=1.75-3.11)$ but lower among female participants $(\mathrm{OR}=0.58 ; 95 \% \mathrm{CI}=0.30-0.79)$. Being a realistic inactive was associated with increasing age, female gender and higher income.

Conclusions: About half of the community dwellers were physically inactive with about half of them having a misperception of their activity levels. Misperceptions and realities about physical activity were generally linked to sociodemographic characteristics. A specially designed educational intervention programme may provide more insight to the community dwellers about their physical activities.

Keywords: physical activity, community dwellers, perceptions

\section{Introduction}

Physical activity is any bodily movement produced by skeletal muscles resulting in energy expenditure (Caspersen, Powell, \& Christenson, 1985). It is an active exercise that requires a deliberate effort to initiate and sustain. Unfortunately, many individuals do not get to be sufficiently active and this is usually linked to many reasons. At the community level, the population may have a number of reasons why they are not physically active, many of which are similar to the ones that have been reported at other levels of dwelling. A previous study had opined that an understanding of the factors that influence physical activity behaviour is critical to developing effective intervention strategies to address physical inactivity among the different populations (Chad et al., 2005). Studies have reported other factors why people have generally remained inactive and these cut across personal, social and environmental issues (Giles-Corti \& Donovan, 2002; Bedimo-Rung, Mowen, \& Cohen, 2005; Chad et al., 2005; Duncan, Spence, \& Mummery, 2005; Roshanaei-Moghaddam, Katon, \& Russo, 2009). 
An important factor in any behavioural activity is having a realistic perception of ones level of engagement in such activities. However, most of the inactive individuals may not have realized that they are actually inactive, with many of them holding tight to the perception that they are physically active. This false perception of ones level of physical activity may have a far reaching implication on the physical activity of such individuals. In some previous studies (Corder et al., 2010, 2011), a substantial number of respondents believed themselves to be more physically active than what they really were and that may have had a lot of implication on their actual physical activity levels. The false perception of physical activity may partly for the reasons why the prevalence of physical activity is fairly high in many settings. For example, the few studies that considered physical activity of apparently healthy adult population in Nigeria had reported a fairly high prevalence of physical inactivity. It had been reported that physical inactivity ranged between $25 \%$ and $57 \%$ for the Nigerian population (Abubakario \& Bhopai, 2008; A. L. Oyeyemi, A. Y. Oyeyemi, Jidda, \& Babagana, 2013).

Lechner, Bolman, and Van Dijke (2005) had opined that increasing the accuracy of people's self-perceptions of physical activity may be an important strategy to promote physical activity in populations at risk of inactivity. Unfortunately, extrapolation of perceptions from studies conducted in other settings may not be entirely appropriate because of the different social and cultural backgrounds of the participants in the different studies (Richter, Wilcox, Greaney, Henderson, \& Ainsworth, 2002; Eyler, Vest, \& Sanderson, 2002). Ability to improve peoples' perception about physical activity will enhance behavioural change, but achieving this will only be possible if different communities assess the perceptions of their residents in order to establish whether or not they have an appropriate perception of their physical activity levels. An important way of assessing their perception is based on their ability to provide an accurate self-rating of their activity efforts. Hence, this study was conducted to determine whether a self-rated physical activity among a group of community dwelling adults in a Nigerian population will be comparable to a more objective researcher-rated physical activity.

\section{Methodology}

\subsection{Study Setting}

Ibadan city, from where this study was conducted is the capital city of Oyo State in Nigeria, and it used to be the administrative capital of the old Western Region of Nigeria. Oyo State with a total of about 4.5 million people is made up of 33 Local Government Areas (LGAs) (oyostate.gov., 2015). Out of the 33 LGAs in Oyo State, the metropolitan Ibadan which accounts for about half of the total population of Oyo State is made up of 11 LGAs (oyostate.gov., 2015). Five of the LGAs are urban LGAs located in the urban Ibadan city and the remaining 6 are semi-urban LGAs located in the less cities of Ibadan (Figure 1). This study took place in 3 randomly selected LGAs out of the 5 LGAs that make up the Ibadan urban city. The selected LGAs were: Ibadan North Local Government (with a population of 306,795), Ibadan North West Local Government (with a population of 152,834) and Ibadan South East Local Government (with a population of 266,046) (oyostate.gov., 2015).

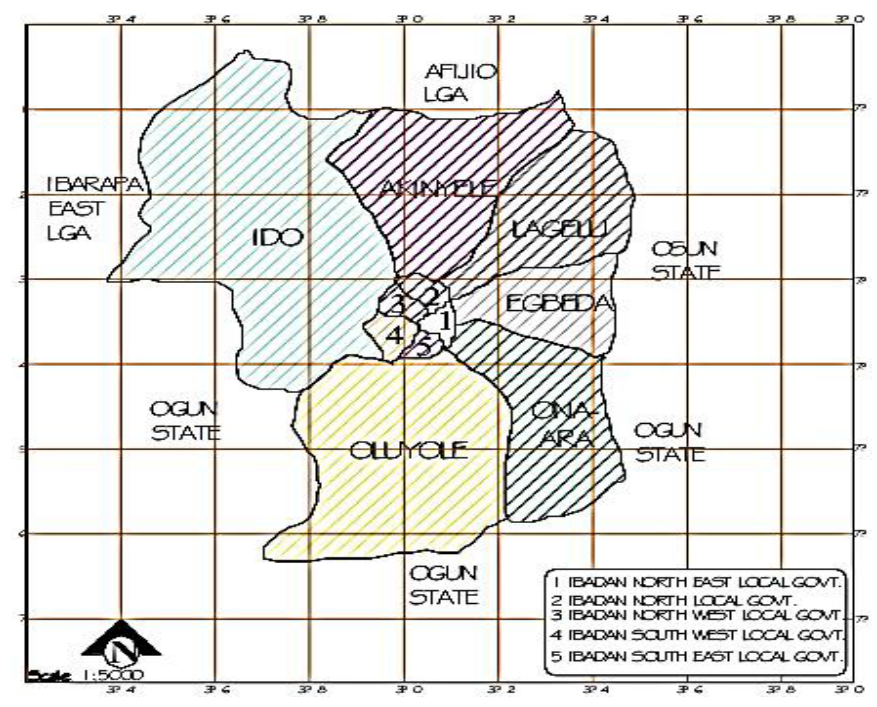

Figure 1. Map of Ibadan showing the study sites (labeled 2, 4 \& 5)

Source. Ministry of Lands and Housing, Ibadan; culled from Adetunji and Oyeleye (2013). 


\subsection{Participants}

Participants for this study were recruited from the adult population (18 years and older) living in the various communities of the 3 selected LGAs between September 2013 and August 2014. A sample size determination formula for a known population using $\mathrm{n}=\mathrm{N} /\left[1+\mathrm{N}(\mathrm{e})^{2}\right]$, \{where $\mathrm{n}=$ sample size to be determined, $\mathrm{N}=$ total population size and e=level of precision $(+5 \%)\}$ (Yamane, 1967) was used to compute sample size for each of the LGAs. This yielded a sample of 400 for each of the LGAs. A total of 450 questionnaires (containing an extra 50 copies) were subsequently distributed in each of the LGAs (making a total of 1,350 for the 3 LGAs). To be eligible to participate in the study, participants were expected to have lived in the community for a minimum of one year. Pregnant women and individuals with obvious physical disabilities were excluded from the study.

\subsection{Procedure}

This study was a cross-sectional survey of community dwellers in 3 randomly selected LGAs out of the 5 LGAs that make up the Ibadan urban city. The survey was conducted at different locations within the three LGAs. Questionnaires were distributed to prospective participants at selected locations that included religious/faith centres (churches/mosques) and other selected centres that are known as the hub of activities including markets, business centres, motor parks and schools. For ease of administration, the data collection centres were located within the political wards that made up each of the selected LGAS. In Ibadan North Local Government, there were 12 political wards, Ibadan North West Local Government had 11, and Ibadan South East Local Government had 12 (OYSIEC, 2015). A total of 50 questionnaires were distributed in 9 wards (that were selected using simple random selection) making a total of 450 questionnaires for each of the selected LGAs. The 450 questionnaires for each of the LGAs were distributed using the non-probability convenience sampling method. At the end of the study, 388, 363 and 402 questionnaires were returned from Ibadan North Local Government, Ibadan North West Local Government and Ibadan South East Local Government respectively. This yielded a total of 1,153 for the 3 LGAs. The good response rate was aided by an adequate participant education about importance of the study, followed by a sustained physical follow-up.

Ethical approval to conduct the study was obtained from the University of Ibadan/University College Hospital Research Ethics Committee. An informed consent stating the purpose of the study as well as assuring participants of confidentiality and anonymity was attached to the questionnaires. The questionnaires were translated to Yoruba language, the indigenous language of the South-west Nigeria. The translation was for the benefit of Yoruba speaking participants who could not understand or speak English.

\subsection{Data Collection and Instrumentation}

Sociodemographic data questionnaire: This was a self-developed questionnaire which consists of items designed to gather sociodemographic data from the participants. Items on the questionnaire sought information on age of participants, sex, and marital status. Others were level of education, employment status, and monthly income.

Assessment of physical activity perception: Two measures were used to assess participants' level of health enhancing physical activity. First measure asked the participants to provide their self-rated level of participation in health enhancing physical activity in relation to a simple and comprehensive physical activity vignette. The vignette set at a moderate level of physical activity described health enhancing physical activity as performing physical activity that makes them sweat and breathe harder for at least 30 minutes a day on five or more days of the week (van Sluijs, Griffin, \& van Poppel, 2007; ACSM, 2015; CDC, 2015). The participants were asked to report whether their physical activity level was the same with what was described, or lower or higher. The second measure was the researcher-rating of health enhancing physical activity level using the Short Questionnaire to Assess Health-Enhancing Physical Activity (SQUASH) (Wendel-Vos, Schuit, Saris, \& Kromhout, 2003). In a previous study, the Spearman's correlation for overall reproducibility of the SQUASH was $0.58(95 \%$-CI $0.36-0.74)$ and correlations for the reproducibility of the separate questions varied between 0.44 and 0.96 (Wendel-Vos et al., 2003). Another study also found a Spearman's correlation coefficient of 0.57 for overall reliability, and between 0.45 and 0.90 for the separate questions (Wagenmakers et al., 2008). The questionnaire was used to determine whether the participants were actually meeting the ACSM/CDC-guideline for health enhancing physical activity. The SQUASH contains questions on commuting activities, leisure time and sports activities, household activities, and activities at work and school. It consists of three main queries: days per week, average time per day and intensity (effort).

Calculation of the activity score per week from the SQUASH: Participants were asked to refer to an average week in the past few months. Using the Ainsworth compendium of physical activities, activities are assigned a MET value. One MET is defined as the energy expenditure for sitting quietly. Activities were subdivided for adults and older adults (up to age 55 and older) respectively into three intensity categories. For adults, activities 
with a MET-value between 2 and $<4$ was classified as low, between 4 and $<6.5$ as moderate, and $\geq 6.5$ as vigorous intensity. For older adults activities between 2 and $<3$ MET was classified as low, between 3 and $<5$ MET as moderate, and $\geq 5$ MET as vigorous intensity. Activities with a MET value lower than 2 were not included because they were considered to contribute negligibly to physical activity level. Based on the questionnaire, activities were assigned an intensity score and a total activity score. Activity scores for separate questions was calculated by multiplying total minutes of activity by the intensity score (Wagenmakers et al., 2008). The participants were categorized from the outcomes of the questionnaire as those having low, moderate or high physical activity levels.

Determination of perception and misperception: Misperception was measured by comparing self-reports of physical activity level with that of a more objective classification carried out by the researchers (Bolman, Lechner, \& van Dijke, 2007). Based on the self-report of physical activity level which was compared to the actual physical activity level of the participant as identified by the SQUASH, the participant was classified into four sub-groups for levels of perceptions: namely the underestimators, overestimators, realistic actives and realistic inactives (Bolman et al., 2007; van Sluijs et al., 2007; Corder et al., 2011). Underestimators were participants that were actually moderately or vigorously active but underrated themselves by claiming that they had low physical activity levels, and overestimators were those that were actually inactive (having low physical activity levels), but overrated themselves as having moderate or vigorous level of physical activity. The realistic actives were those that were actually moderately or vigorously active and were able to correctly describe themselves as such, while the realistic inactives were those who were physically inactive and were able to correctly describe themselves as having low physical activity levels.

\subsection{Data Analyses}

Data were summarized using percentages. A side by side analysis of the participants' and researcher-rated physical activity outcomes were carried out to identify those who had the correct and wrong assessments of their physical activity levels. Based on the comparison, 4 categories of perceptions emerged: the underestimators, overestimators, and realistic active and realistic inactives. The influence of sociodemographic characteristics of age, sex, marital status, employment, etc. on the four categories of perception of the participants were tested using multiple logistic regression analyses. The logistic regression was used to calculate the odds ratio (OR) of being underestimators, overestimators, and realistic active and realistic inactives. A p value of 0.05 was considered statistically significant. All statistical analyses were carried out using IBM SPSS version 20 statistics for Windows (SPSS Inc., Chicago, IL, USA) at $\alpha<0.05$.

\section{Results}

At the end of the study, 388 (86.2\%), $363(80.7 \%)$ and 402 (89.3\%) questionnaires were returned from Ibadan North Local Government, Ibadan North West Local Government and Ibadan South East Local Government respectively. This yielded a total of 1,153 for the 3 LGAs. The sociodemographic characteristics of participants in this study are as presented in table 1 . Most (66.4\%) of the participants were male community dwellers with age group 31 to 40 years constituting more than one third (35.7\%) of the participants. More than half of the population $(56.6 \%)$ was self-employed with $50.2 \%$ of the population earning less than 50,000 Nigerian Naira $(<250$ US Dollars) per month.

Table 2 shows that only one fifth (23.3\%) of the community dwellers rated themselves as having low physical activity levels, whereas in reality, more than half of the population $(52.4 \%)$ was actually inactive. With respect to their perception of physical activity, it means that 335 (29.1\%) of the community dwellers overestimated their physical activity level. Two groups of realists emerged: the realistic inactive group that correctly rated themselves as inactive made up of a total of $23.3 \%$ of the participants and a larger realistic active group made up of 518 (44.9\%) participants. The latter group was made up of those who were able to correctly rate themselves as physically active; made up of those who presented with moderate to high physical activity levels. Only a small proportion $(2.7 \%)$ of the community dwellers underestimated their physical activity levels by claiming that they had moderate physical activity level whereas they actually had high physical activity levels.

Table 3 shows the factors that are linked with the odds of having a misperception of physical activity (being an underestimator or overestimator). Compared with the youngest age group, community dwellers in the age category of 41-50 had more than double the odds of overestimating their physical activity levels (OR=2.16; $95 \%$ $\mathrm{CI}=1.75-3.11)$. It was noted however that the female community dwellers had lesser risk of overestimation of their physical activity $(\mathrm{OR}=0.58 ; 95 \% \mathrm{CI}=0.30-0.79)$ compared to their male counterparts. The participants were however less likely to underestimate if they were older, females, married, with higher educational level and being employed, although only significant for the age categories. The odds of being a reslistically active or 
inactive person is presented in table 4 . The table shows that those who are physically inactive and realistic about it are likely to be those who are older, females and with primary level of education. Being 60 years and above was associated with the highest odd of being a realistic active $(\mathrm{OR}=3.34 ; 95 \% \mathrm{CI}=2.16-4.89)$.

Table 1. Sociodemographic characteristics of the participants

\begin{tabular}{|c|c|c|}
\hline Sociodemographic characteristic & $\mathbf{N}$ & $\%$ \\
\hline \multicolumn{3}{|l|}{ Age } \\
\hline $18-30$ & 306 & 26.5 \\
\hline $31-40$ & 411 & 35.7 \\
\hline $41-50$ & 118 & 10.2 \\
\hline $51-60$ & 220 & 19.1 \\
\hline$>60$ & 98 & 8.5 \\
\hline \multicolumn{3}{|l|}{ Sex } \\
\hline Male & 766 & 66.4 \\
\hline Female & 387 & 33.6 \\
\hline \multicolumn{3}{|l|}{ Marital status } \\
\hline Single & 314 & 27.2 \\
\hline Married & 797 & 69.1 \\
\hline Divorced & 42 & 3.7 \\
\hline \multicolumn{3}{|l|}{ Level of education } \\
\hline Nil & 138 & 12.0 \\
\hline Primary level & 194 & 16.8 \\
\hline Secondary level & 601 & 52.1 \\
\hline Tertiary & 220 & 19.1 \\
\hline \multicolumn{3}{|l|}{ Occupational status } \\
\hline Unemployed & 325 & 28.2 \\
\hline Self-employed & 652 & 56.6 \\
\hline Paid employment & 176 & 15.2 \\
\hline \multicolumn{3}{|l|}{ Earned monthly income } \\
\hline$<50,000(<$ USD 250) & 579 & 50.2 \\
\hline 50,000-100,000 (USD 250-500) & 471 & 40.9 \\
\hline$>100,000(>$ USD 500) & 103 & 8.9 \\
\hline
\end{tabular}

Table 2. Outcomes of self and researcher estimates of physical activity among the community dwellers

\begin{tabular}{|c|c|c|c|c|c|c|}
\hline & & Category of perception & & & & \\
\hline & & & $\begin{array}{l}\text { Under-estimators } \\
\text { n (\%) }\end{array}$ & $\begin{array}{l}\text { Over-Estimators } \\
\text { n (\%) }\end{array}$ & $\begin{array}{l}\text { Realistic } \\
\text { actives } \\
\text { n (\%) }\end{array}$ & $\begin{array}{l}\text { Realistic } \\
\text { inactives } \\
\text { n (\%) }\end{array}$ \\
\hline & $\begin{array}{l}\text { Self-rated } \\
\text { physical activity } \\
\text { level } \\
\text { n (\%) }\end{array}$ & $\begin{array}{l}\text { Researcher-rated } \\
\text { physical activity level } \\
\text { n (\%) }\end{array}$ & & & & \\
\hline \multicolumn{7}{|l|}{$\begin{array}{l}\text { Physical activity } \\
\text { level }\end{array}$} \\
\hline $\begin{array}{l}\text { Low physical } \\
\text { activity level }\end{array}$ & $269(23.3)$ & $604(52.4)$ & $\mathrm{N} / \mathrm{A}$ & $335(29.1)$ & N/A & $269(23.3)$ \\
\hline $\begin{array}{l}\text { Moderate } \\
\text { physical activity } \\
\text { level }\end{array}$ & $697(60.5)$ & $331(28.7)$ & $\mathrm{N} / \mathrm{A}$ & N/A & $331(28.7)$ & N/A \\
\hline \multirow{2}{*}{$\begin{array}{l}\text { High physical } \\
\text { activity level }\end{array}$} & $187(16.2)$ & 218 (18.9) & $31(2.7)$ & $\mathrm{N} / \mathrm{A}$ & $187(16.2)$ & N/A \\
\hline & Total & 1,153 & $31(2.7)$ & $335(29.1)$ & $518(44.9)$ & $269(23.3)$ \\
\hline
\end{tabular}

$\mathrm{N} / \mathrm{A}=$ Not applicable. 
Table 3. Factors associated with underestimation and overestimation of physical activity among the community dwellers

\begin{tabular}{lll}
\hline & $\begin{array}{l}\text { Underestimators } \\
\text { OR (95\% CI) }\end{array}$ & $\begin{array}{l}\text { Overestimators } \\
\text { OR (95\% CI) }\end{array}$ \\
\hline Age & 1 & 1 \\
$18-30$ & $2.15(1.31-2.54)^{*}$ & $1.36(0.85-2.18)$ \\
$31-40$ & $0.81(0.61-1.68)$ & $2.16(1.75-3.11)^{*}$ \\
$41-50$ & $0.83(0.67-1.96)$ & $1.32(0.78-1.67)$ \\
$51-60$ & $0.62(0.33-0.89)^{*}$ & $1.36(0.98-2.66)$ \\
$>60$ & & \\
Sex & 1 & 1 \\
Male & $0.64(0.21-1.62)$ & $0.58(0.30-0.79)^{*}$ \\
Female & & 1 \\
Marital status & 1 & $1.21(0.59-2.21)$ \\
Single & $0.67(0.19-2.10)$ & $1.26(0.88-2.84)$ \\
Married & $0.74(0.31-1.79)$ & 1 \\
Divorced & & $0.48(0.22-1.18)$ \\
Level of education & 1 & $0.63(0.38-2.15)$ \\
Nil & $0.68(0.44-1.65)$ & $0.49(0.16-1.66)$ \\
Primary level & $0.68(0.56-1.84)$ & 1 \\
Secondary level & $0.75(0.40-1.59)$ & $1.19(0.84-2.13)$ \\
Tertiary & & $0.54(0.23-1.63)$ \\
Occupational status & 1 & $0.36(0.11-1.17)$ \\
Unemployed & $0.71(0.34-1.23)$ & \\
Self-employed & $0.66(0.31-1.54)$ & \\
Paid employment & 1 & $1.30(0.96-2.41)$ \\
Earned monthly income & $1.21(0.65-1.77)$ & \\
$<50,000(<$ USD 250) & & \\
$50,000-100,000$ (USD 250-500) & & \\
$>100,000$ (>USD 500) & & \\
\hline$*$ Significat & & \\
\hline
\end{tabular}

*Significant at $\mathrm{p}<0.05$.

Table 4. Factors associated with having realistic perceptions of physical activity (realistic active \& realistic inactives) among the community dwellers

\begin{tabular}{lll}
\hline Age & $\begin{array}{l}\text { Realistic active } \\
\text { OR } \mathbf{( 9 5 \%} \text { CI) }\end{array}$ & $\begin{array}{l}\text { Realistic inactive } \\
\text { OR (95\% CI) }\end{array}$ \\
$18-30$ & 1 & 1 \\
$31-40$ & $1.26(0.85-2.63)$ & $1.83(1.23-3.17)^{*}$ \\
$41-50$ & $1.26(0.37-2.14)$ & $1.67(1.13-2.49)^{*}$ \\
$51-60$ & $1.49(0.91-2.66)$ & $2.42(1.21-3.68)^{*}$ \\
$>60$ & $3.34(2.16-4.89)^{*}$ & $2.77(1.46-4.22)^{*}$ \\
Sex & & 1 \\
Male & 1 & $2.1(1.55-3.41)^{*}$ \\
Female & $2.16(1.57-3.67)^{*}$ & \\
Marital status & & 1 \\
Single & 1 & $1.34(0.63-2.10)$ \\
Married & $2.32(1.87-3.86)^{*}$ & \\
\hline
\end{tabular}




\begin{tabular}{lll}
\hline $\begin{array}{l}\text { Divorced } \\
\text { Level of education }\end{array}$ & $1.26(0.46-2.30)$ & $1.25(0.71-2.61)$ \\
Nil & 1 & 1 \\
Primary level & $1.14(0.82-1.88)$ & $1.84(1.23-3.16)^{*}$ \\
Secondary level & $2.14(1.58-3.42)^{*}$ & $1.24(0.68-1.81)$ \\
Tertiary & $2.399(1.72-4.11)^{*}$ & $1.41(0.59-1.33)$ \\
Occupational status & & \\
Unemployed & 1 & 1 \\
Self-employed & $1.96(1.12-2.86)^{*}$ & $1.12(0.56-1.83)$ \\
Paid employment & $1.38(0.79-2.16)$ & $1.35(0,57-1.99)$ \\
Earned monthly income & & \\
$<50,000(<$ USD 250) & 1 & 1 \\
50,000-100,000 (USD 250-500) & $0.79(0.26-0.95)^{*}$ & $1.67(1.21-2.14)^{*}$ \\
$>100,000(>$ USD 500) & $0.51(0.22-0.91)^{*}$ & $1.82(1.34-2.66)^{*}$ \\
\hline
\end{tabular}

*Significant at $\mathrm{p}<0.05$.

\section{Discussion}

The main focus of this study was to have a set of Nigerian community dwellers to rate their own physical activity and have their response compared with that of a more objective rating by the researchers in order to establish whether they have a good perception of their physical activity performance. This stemmed from an assumption that a behavioural change will be easier if the people concerned are able to have a fairly accurate perception of their actions or inactions. With respect to health risk behaviour, it has been reported that many people are unaware of their own risk behaviour and usually assume that their behaviour is healthier than it really is (Lechner et al., 2006; Coder et al., 2010). The major findings from this current study include the fact that 1) more than half of the community dwellers were inactive, whereas only about one fifth of the population correctly reported this, 2) concerning perception of their physical activity, one third actually overestimated themselves, a smaller proportion was able to accurately rate themselves as inactive, about half rated themselves accurately as active with only a small proportion underestimating themselves, and 3) the community dwellers that were likely to overestimate their physical activity levels were those in their middle-age with higher income while those who were females, married, with higher education and in employment were less likely to overestimate.

Low physical activity in more than half of the community dwellers was only corroborating the general outlook of physical activity among community dwellers in studies that were conducted in other parts of the globe. Generally, physical activity is low among many populations with a global prevalence of physical inactivity ranging between $24 \%$ and $62 \%$ (Macera et al., 2003; Kruger, Ham, Kohl, \& Sapkota, 2004; Al-Hazzaa, 2004; Dumith, Hallal, Reis, \& Kohl III, 2011). Compared to the current study, a previous study had reported a lower prevalence of physical inactivity of $31.4 \%$ (Oyeyemi et al., 2013), although that study was conducted in the Northwestern region of Nigeria while the current study was conducted in the Southwestern region of Nigeria, However, it is important to note that participants in the current study were community dwelling individuals who live essentially in high density areas with closely knitted residential buildings, heavy human and vehicular traffic, street trading, on-walkway parking of automobiles and low walkability areas. Adults from neighbourhoods with high walkability areas have been reported to have more than 70 more minutes of physical activity than residents of low walkability neighbourhoods (Saelens, Sallis, Black, \& Chen, 2003). As sizeable as the proportion of low physical activity was in this study, it was interesting to note that only a small proportion of the participants could accurately report it. This misperception of their physical activity level earned them their classification as overestimators.

At the moment, there are no previous studies from this environment to compare this present study with. However, previous studies from other regions of the globe found this to be a general problem which cuts across all age groups. In a UK adolescent population, a study had found that approximately $70.1 \%$ of adolescents were inactive with $52.6 \%$ of all girls and $33.6 \%$ of all boys inaccurately rating themselves as active (overestimators) (Corder et al 2011). The situation seems to be similar in an earlier study also in the UK, but among children where about $40 \%$ of them overestimated their physical activity (Corder et al., 2010). Unfortunately, in that report (Corder et al., 2010), it was discovered that up to $80 \%$ of the parents of inactive children actually wrongly thought that their 
children were sufficiently active. In the adult population, a study in England also reported $45.9 \%$ overestimators (Watkinson et al., 2010) and another in the Netherlands reported 61.4\% (van Sluijs et al., 2007).

The attitude of overestimation of physical activity has the unfortunate potential of making the individual less active as the individual feels he or she is already active at the recommended levels, hence such individuals will not likely strive to perform any better. People often have misperceptions (overestimation or underestimation) about the health-related behaviours they engage in, and that usually affects their behavioural change (Bolman et al., 2007; Watkinson et al., 2010). Such people believe themselves to be more physically active than they really are and they may be unaware of potential health risks (Lechner et al., 2006; Coder et al., 2011) and also unlikely to participate in physical activity promotion programmes (van Sluijs et al., 2007; Coder et al., 2011). Hence, increasing the accuracy of people's self-perceptions of physical activity may be an important issue to be incorporated into strategies to promote physical activity in populations at risk of inactivity (Lechner et al., 2006; van Sluijs et al., 2007; Corder et al., 2010).

It was found that the community dwellers who were older, more educated and richer were the ones with the higher misperceptions about their physical activities. The reason for this is not known. It could be that they were genuinely unaware of their physical inactivity, or could be an effort to cover up their inactivity in view of their higher socioeconomic status. For instance, social desirability was associated with over-reporting of activity, resulting in overestimation of physical activity energy expenditure and overestimation of activity durations (Adams et al., 2005). In the study by Corder et al. (2011), they had also reported that compared with realistic inactive girls (28.6\%), the girl overestimators had higher socioeconomic status (high vs low OR, 2.38; 95\% CI, 1.07-5.32), more parent support (OR, 1.57; 95\% CI, 1.12-2.22), and better family relationships (OR, $0.25 ; 95 \% \mathrm{CI}$, 0.09-0.67). Similar to their current study, van Sluijs et al (2007) had also observed overestimation to be more among the older population.

One of the main relevance of this study is that it has helped to reveal the level of misperception that exists among a typical community dwelling population of a developing country with respect to physical activity performance. The outcome of the study underscores the need for massive physical activity education in order to make them have a more realistic view of their physical activity. If this is achieved, it may help to improve their physical activity levels. Some previous studies had emphasized the importance of mass campaigns to promote regular activity with the studies further stressing that such campaigns had positively influenced short-term physical activity message recall, knowledge, and behavior of the target population, compared to the population in the region who were not exposed to such campaigns (Bauman, Bellew, Owen, \& Vita, 2001; Hillsdon, Cavill, Nanchahal, Diamond, \& White, 2001). In a review that identified interventions to improve physical activity programmes from around the world, the informational approaches of community-wide mass media campaigns, and short physical activity messages targeting key community sites were recommended (Heath et al., 2012). However, a major limitation in this study bothers on the method of data collection which was essentially interview-based. This has a major potential for a recall bias hence the need to interpret results with caution. According to Shephard, (2003), despite the extensive use of over 40 years, physical activity questionnaires still show limited reliability and validity. That notwithstanding, questionnaires are still reported as one of the best and practical measures of physical active at population levels (Booth, Owen, Bauman, \& Gore, 1996). In addition, participants in this study were educated on the need to take their time to complete the questionnaires with the view to providing responses that were as accurate as possible.

\section{Conclusions}

In conclusion, it was observed that most of the community dwellers were physically inactive and a substantial number of those who were inactive could not accurately report that they were inactive. They exhibited wrong perceptions about their physical activity levels with most of them overestimating themselves. Misperceptions about physical activity were generally linked to sociodemographic characteristics with higher possibility of overestimation found among the middle-aged with higher income. There is a need for a specially designed educational programme capable of providing more insight to the community dwellers concerning issues in physical activity participation.

\section{Competing Interests Statement}

The authors declare that there is no conflict of interests regarding the publication of this paper.

\section{References}

Abubakari, A. R., \& Bhopal, R. S. (2008). Systematic review on the prevalence of diabetes, overweight/obesity and physical inactivity in Ghanaians and Nigerians. Public Health, 122(2), 173-182. http://dx.doi.org/10. 
1016/j.puhe.2007.06.012

Adams, S. A., Matthews, C. E., Ebbeling, C. B., Moore, C. G., Cunningham, J. E., Fulton, J., \& Hebert, J. R. (2005). The effect of social desirability and social approval on self-reports of physical activity. American Journal of Epidemiology, 161(4), 389-398. http://dx.doi.org/10.1093/aje/kwi054

Adetunji, M., \& Oyeleye, O. (2013). Evaluation of the causes and effects of flood in Apete, Ido Local Government Area, Oyo State, Nigeria. Civil and Environmental Research, 3(7), 19-26.

Al Hazzaa, H. M. (2004). Prevalence of physical inactivity in Saudi Arabia: A brief review. Eastern Mediterranean Health Journal, 10(4-5), 663-670.

American College of Sports Medicine (ACSM). (2015). Retrieved from http://www.acsm.org/aboutacsm/media -room/news-releases/2011/08/01/acsm-issues-new-recommendations-on-quantity-and-quality-of-exercise

Bauman, A. E., Bellew, B., Owen, N., \& Vita, P. (2001). Impact of an Australian mass media campaign targeting physical activity in 1998. American Journal of Preventive Medicine, 21(1), 41-47. http://dx.doi.org/10. 1016/S0749-3797(01)00313-0

Bedimo-Rung, A. L., Mowen, A. J., \& Cohen, D. A. (2005). The significance of parks to physical activity and public health: A conceptual model. American Journal of Preventive Medicine, 28(2), 159-168. http://dx.doi.org/10.1016/j.amepre.2004.10.024

Bolman, C., Lechner, L., \& van Dijke, M. (2007). Question order in the assessment of misperception of physical activity. International Journal of Behavioral Nutrition and Physical Activity, 4, 42. http://dx.doi.org/10. 1186/1479-5868-4-42

Booth, M. L., Owen, N., Bauman, A. E., \& Gore, C. J. (1996). Retest reliability of recall measures of leisure-time physical activity in Australian adults. International Journal of Epidemiology, 25, 153-159. http://dx.doi.org/10.1093/ije/25.1.153

Caspersen, C. J., Powell, K. E., \& Christenson, G. M. (1985). Physical activity, exercise, and physical fitness: Definitions and distinctions for health-related research. Public health reports, 100(2), 126-131.

Centre for Disease Control and Prevention (CDC). (2015). Retrieved June 23, 2015, from http://www.cdc.gov/physicalactivity/basics/adults/index.htm

Chad, K. E., Reeder, B. A., Harrison, E. L., Ashworth, N. L., Shephard, S. M., Schultz, S. L., ... Lawson, J. A. (2005). Profile of physical activity levels in community-dwelling older adults. Medicine and Science in Sports and Exercise, 37(10), 1774-1784. http://dx.doi.org/10.1249/01.mss.0000181303.51937.9c

Corder, K., van Sluijs, E. M. F., Goodyer, I., Ridgway, C. L., Steele, R. M., Bamber, D., ... Ekelund, U. (2011). Physical activity awareness of British adolescents. Archives of Pediatric and Adolescent Medicine, 165(7), 603-609. http://dx.doi.org/10.1001/archpediatrics.2011.94

Corder, K., van Sluijs, E. M. F., McMinn, A. M., Ekelund, U., Cassidy, A., \& Griffin, S. J. (2010). Perception versus reality: Awareness of physical activity levels of British children. American Journal of Preventive Medicine, 38(1), 1-8. http://dx.doi.org/10.1016/j.amepre.2009.08.025

Dumith, S. C., Hallal, P. C., Reis, R. S., \& Kohl III, H. W. (2011). Worldwide prevalence of physical inactivity and its association with human development index in 76 countries. Preventive Medicine, 53(1-2), 24-28. http://dx.doi.org/10.1016/j.ypmed.2011.02.017

Duncan, M. J., Spence, J. C., \& Mummery, W. K. (2005). Perceived environment and physical activity: A meta-analysis of selected environmental characteristics. International Journal of Behavioral Nutrition and Physical Activity, 2, 11. http://dx.doi.org/10.1186/1479-5868-2-11

Eyler, A. A., Vest, J. R., Sanderson, B., Wilbur, J., Matson-Koffman, D., Evenson, K. R., ... Young, D. R. (2002). Environmental, policy, and cultural factors related to physical activity in a diverse sample of women: The Women's Cardiovascular Health Network Project-introduction and methodology. Women \& Health, 36(2), 1-15. http://dx.doi.org/10.1300/J013v36n02_01

Giles-Corti, B., \& Donovan, R. J. (2002). The relative influence of individual, social and physical environment determinants of physical activity. Social Science \& Medicine, 54(12), 1793-1812. http://dx.doi.org/10.1016/ S0277-9536(01)00150-2

Heath, G. W., Parra, D. C., Sarmiento, O. L., Andersen, L. B., Owen, N., Goenka, S., ... The Lancet Physical Activity Series Working Group. (2012). Evidence-based intervention in physical activity: Lessons from 
around the world. The Lancet, 380(9838), 272-281. http://dx.doi.org/10.1016/S0140-6736(12)60816-2

Hillsdon, M., Cavill, N., Nanchahal, K., Diamond, A., \& White, I. R. (2001). National level promotion of physical activity: Results from England's ACTIVE for LIFE campaign. Journal of Epidemiology and Community Health, 55, 755-761. http://dx.doi.org/10.1136/jech.55.10.755

Kruger, J., Ham, S. A., Kohl, H. W., \& Sapkota, S. (2004). Physical activity among Asians and native Hawaiian or other Pacific Islanders-50 states and the District of Columbia, 2001 2003. Morbidity and Mortality Weekly Report, 53(33), 756-760.

Lechner, L., Bolman, C., \& Van Dijke, M. (2006). Factors related to misperception of physical activity in The Netherlands and implications for health promotion programmes. Health Promotion International, 21(2), 104-112. http://dx.doi.org/10.1093/heapro/dal011

Macera, C. A., Jones, D. A., Yore, M. M., Ham, S. A., Kohl, H. W., Kimsey, C. D. Jr., \& Buchner, D. (2003). Prevalence of physical activity, including lifestyle activities among adults United States, 2000-2001. Morbidity and Mortality Weekly Report, 52(32), 766-769.

Oyeyemi, A. L., Oyeyemi, A. Y., Jidda, Z. A., \& Babagana, F. (2013). Prevalence of physical activity among adults in a metropolitan Nigerian city: A cross-sectional study. Journal of Epidemiology, 23(3), 169-177. http://dx.doi.org/10.2188/jea.JE20120116

Oyo State Independent Electoral Commission (OYSIEC). (2015). Retrieved August 11, 2015, from http://www.oysiec.org/oysiec/lgas.php

Oyostate.gov. (2015). Retrieved August 11, 2015, from http://www.oyostate.gov.ng/

Richter, D. L., Wilcox, S., Greaney, M. L., Henderson, K. A., \& Ainsworth, B. E. (2002). Environmental, policy, and cultural factors related to physical activity in African American women. Women \& Health, 36(2), 89-107. http://dx.doi.org/10.1300/J013v36n02_07

Roshanaei-Moghaddam, B., Katon, W. J., \& Russo, J. (2009). The longitudinal effects of depression on physical activity. General Hospital Psychiatry, 31(4), 306-315. http://dx.doi.org/10.1016/j.genhosppsych. 2009.04.002

Saelens, B. E., Sallis, J. F., Black, J. B., \& Chen, D. (2003). Neighborhood-based differences in physical activity: An environment scale evaluation. American Journal of Public Health, 93(9), 1552-1558. http://dx.doi.org/10.2105/AJPH.93.9.1552

Shephard, R. J. (2003). Limits to the measurement of habitual physical activity by questionnaires. British Journal of Sports Medicine, 37, 197-206. http://dx.doi.org/10.1136/bjsm.37.3.197

van Sluijs, E. M. F., Griffin, S. J., \& van Poppel, M. N. M. (2007). A cross-sectional study of awareness of physical activity: Associations with personal, behavioral and psychosocial factors. International Journal of Behavioral Nutrition and Physical Activity, 4, 53. http://dx.doi.org/10.1186/1479-5868-4-53

Wagenmakers, R., van den Akker-Scheek, I., Groothoff, J. W., Zijlstra, W., Bulstra, S. K., Kootstra, J. W. J., ... Stevens, M. (2008). Reliability and validity of the short questionnaire to assess health-enhancing physical activity (SQUASH) in patients after total hip arthroplasty. BMC Musculoskeletal Disorders, 9, 141. http://dx.doi.org/10.1186/1471-2474-9-141

Watkinson, C., van Sluijs, E. M., Sutton, S., Hardeman, W., Corder, K., \& Griffin, S. J. (2010). Overestimation of physical activity level is associated with lower BMI: A cross-sectional analysis. International Journal of Behavioral Nutrition and Physical Activity, 20(7), 68. http://dx.doi.org/10.1186/1479-5868-7-68

Wendel-Vos, G. C., Schuit, A. J., Saris, W. H., \& Kromhout, D. (2003). Reproducibility and relative validity of the short questionnaire to assess health-enhancing physical activity. Journal of Clinical Epidemiology, 56(12), 1163-9. http://dx.doi.org/10.1016/S0895-4356(03)00220-8

Yamane, T. (1967). Statistics, an introductory analysis (2nd ed.). New York: Harper and Row.

\section{Copyrights}

Copyright for this article is retained by the author(s), with first publication rights granted to the journal.

This is an open-access article distributed under the terms and conditions of the Creative Commons Attribution license (http://creativecommons.org/licenses/by/3.0/). 